\title{
DESIGN URBANO: A INSERÇÃO DAS CONSTRUÇÕES SUSTENTÁVEIS
}

\author{
URBAN DESIGN: THE INTEGRATION OF SUSTAINABLE BUILDINGS
}

Cristiane Silva ${ }^{1}$

Romualdo Theophanes de França Júnior ${ }^{2}$

Adelcio Machado dos Santos ${ }^{3}$

\section{RESUMO}

Objetiva-se tratar os principais conceitos, características e peculiaridades das cidades sustentáveis, principalmente no que tange a caracterização das construções sustentáveis, como fator destacado, nos recentes processos de planejamento e gestão do espaço urbano. Para tanto abordou-se acerca da paisagem urbana como recurso de desenvolvimento, o desenvolvimento sustentável e sustentabilidade, as construções verdes ou sustentáveis e a sustentabilidade urbana. Conclui-se que inserir as construções sustentáveis no contexto das cidades é uma ferramenta para o design urbano beneficiando a sociedade e gerando desenvolvimento econômico sem afetar as necessidades das futuras gerações, além de evidenciar que o desenvolvimento de técnicas construtivas, aliada a aplicação de materiais ecológicos, respeitando a disponibilidade dos recursos naturais da região produz efeito cultural contribuindo para a sustentabilidade urbana.

Palavras-Chave: Sustentabilidade Urbana. Cidades. Desenvolvimento sustentável.

\section{ABSTRACT}

The objective is to deal with the main concepts, characteristics and peculiarities of

\footnotetext{
${ }^{1}$ Advogada (OAB/SC 27.513) graduada em Direito pela Universidade do Vale do Itajaí - UNIVALI; Mestra em Gestão de Políticas Públicas pela Universidade do Vale do Itajaí - UNIVALI e Doutoranda em Administração da mesma instituição.e-mail: cristianesilva@estadao.com.br.

${ }^{2}$ Mestre em Infraestrutura e Gerência Viária; Engenheiro Civil; Docente da Universidade do Estado de Santa Catarina - UDESC; Doutorando em Administração e Turismo pela Universidade do Vale do Itajaí - UNIVALI, Itajaí, Santa Catarina, Brasil. e-mail: romaphanes@hotmail.com.

${ }^{3}$ Doutor em Engenharia e Gestão do Conhecimento (UFSC). Docente e Pesquisador dos Programas de Pós-Graduação "Stricto Sensu" em Desenvolvimento e Sociedade e Educação da Universidade Alto Vale do Rio do Peixe (Uniarp). Endereço: Rua Prof. Egídio Ferreira, no 271, Apto. 303, bloco "E", Florianópolis (SC) Brasil. E-mail: adelciomachado@gmail.com.
} 
sustainable cities, especially with regard to the characterization of sustainable buildings, as a prominent factor, in the recent urban planning and management processes. In order to do so, it was approached about the urban landscape as a resource for development, sustainable development and sustainability, green or sustainable constructions and urban sustainability. It is concluded that inserting sustainable constructions in the context of cities is a tool for urban design benefiting society and generating economic development without affecting the needs of future generations, as well as evidence that the development of constructive techniques, combined with the application of ecological materials, Respecting the availability of the natural resources of the region produces cultural effect contributing to the urban sustainability.

Keywords: Urban Sustainability. Cities. Sustainable development.

\section{INTRODUÇÃO}

O presente trabalho objetiva tratar os principais conceitos, características e peculiaridades das cidades sustentáveis, principalmente no que tange a caracterização das construções sustentáveis, como fator destacado, nos recentes processos de planejamento e gestão do espaço urbano.

Face aos modelos convencionais da boa forma urbana, o caráter atípico dos novos tecidos, o desenho fragmentado e difuso das novas paisagens urbanas, as rupturas de escala, os efeitos de centrifugação e de (re)polarização, e da nova escala dos territórios urbanizados entre outros temas, produzem um vasto campo de indagação sobre o que realmente interessa para a reflexão e para a reformulação das políticas urbanas vigentes (DOMINGUES, 2006).

Neste contexto, dos vários aspectos que envolvem o design urbano, é que tentamos trazer para a ponta do debate os aspectos referentes às cidades sustentáveis, como, por exemplo, qual a definição fornecida para estas cidades e quais as estratégias aplicadas na sustentabilidade urbana.

\section{A PAISAGEM URBANA COMO RECURSO DE DESENVOLVIMENTO}

É cada vez mais comum o processo de investimento para criar, restaurar, reorganizar, ou mesmo revitalizar as paisagens de uma cidade transformando-as em atrativos para o seu desenvolvimento, seja através do turismo ou mesmo para 
incentivar a instalação de novas empresas.

Este processo de intervenção sobre a paisagem urbana para aumentar a potencialidade competitiva das localidades contribui para alterar a imagem das cidades, principalmente naquelas possuidoras de atrativos culturais expressivos, seja com intervenção no patrimônio, seja pela revitalização de áreas degradadas ou abandonadas, pela gentrificação de grandes áreas da cidade ou mesmo pela inserção de novos artefatos culturais e grandes equipamentos, acabam por influenciar de forma perene a relação homem-espaço (BESSA et al., 2008).

É aqui que propomos a inserção das construções sustentáveis como fator relevante para reorganização do meio urbano, sem perder o foco de seu desenvolvimento. "Cidades como Cingapura, optaram por um planejamento centralizado, privilegiando a melhoria da qualidade ambiental e sanitária da cidade e atraindo empresas de serviços com forte investimento publico em educação, saúde e transporte coletivo" (MOURA, 2004, p. 1). Dubai investe em grandes equipamentos de arquitetura espetacular (NEVE, 2005). De resultado as localidades citadas conquistaram considerável aumento do fluxo turístico incrementando suas economias e melhorando o padrão de qualidade de vida de seus habitantes.

Com a busca incessante do desenvolvimento sustentável nas mais diversas áreas da sociedade, fica implícita a expectativa de novidade, criatividade e inovação no design das construções sustentáveis inseridas como atrativos urbanos. Representa, portanto, uma cultura a ser difundida tanto para os empreendimentos particulares quanto para as edificações públicas.

\section{DESENVOLVIMENTO SUSTENTÁVEL E SUSTENTABILIDADE}

Ao versar sobre a concepção de sustentabilidade, insta registrar, inicialmente, que esta é considerada uma expressão muito utilizada atualmente e que reflete questões fundamentais e que bastante corroboram com o desenvolvimento do planeta.

O termo "desenvolvimento sustentável" foi utilizado pela primeira vez, durante o debate havido no âmbito das políticas internacionais, pelo World Conservation Srategy (SPANGENBERG, 2001). 
Para Ferreira e Amado (2009), existem inúmeros debates sobre a concreta existência do desenvolvimento sustentável. Esses debates têm tomado grande vulto e mencionam a dicotomia existente entre as expressões desenvolvimento e sustentabilidade, além, é claro, de apresentarem um histórico de se escolher por uma ou outra realidade.

O World Wide Fund For Nature ou Fundo Mundial para a Natureza define o desenvolvimento sustentável como um desenvolvimento capaz de suprir as necessidades presentes na atual geração, sem que se afetem as capacidades de atendimento àquelas necessidades das futuras gerações.

Por esses motivos, conclui-se com base em todos os entendimentos proferidos pelo assunto, que o desenvolvimento sustentável ou a sustentabilidade se constitui de um processo que busca compreender um espaço de possibilidades (COELHO, 2001).

É através desse processo que se deseja conciliar o desenvolvimento econômico e a preservação ambiental, refletida através das construções ecológicas, e sua interface no desenho da paisagem urbana.

\section{CONSTRUÇÕES VERDES OU SUSTENTÁVEIS}

Quando se fala de construções verdes ou também chamadas de construções sustentáveis ou ecológicas, há de destacar, primeiramente, que ainda existem muitas discussões sobre a sua concepção e que não é correto afirmar apenas, que uma obra é sustentável ou não, pois a caracterização da sustentabilidade importa a projeção, a execução e somatória de técnicas empregadas com relação ao entorno e ao lugar em que se realiza o empreendimento ou construção (BUSSOLOTI, 2007).

Só é possível afirmar se uma obra é sustentável ou não, se for comparada com outro projeto de uma construção mais sustentável. Por isso:

Pensar em um edifício isolado não faz sentido quando tratamos de questões ambientais como a sustentabilidade dos espaços construídos pelo homem. Por ser sistêmica, a construção para ser sustentável deve ser elaborada em um contexto, o externo é tão importante quanto o que ocorre nas dependências internas. Por isso, a comparação é a melhor forma de avaliar uma construção sustentável, a obra nunca está sozinha (BUSSOLOTI, 2007, p. 1). 
Se um edifício cumprir todos os pré-requisitos técnicos, respeitar todas as normas éticas ambientais, apenas usar materiais adequados e mesmo assim se fechar para dentro, não condizendo com as necessidades do entorno, não se relacionando com o lugar na qual está inserida, abstrair as outras construções e pessoas que convivem próximo, não estará sendo sustentável.

Pode parecer complicado, mas, não existe nenhuma obrigatoriedade de se cumprir todos os requisitos técnicos para uma construção ser sustentável. Caso contrário, as casas seriam todas iguais. Na verdade, as diretrizes são uma forma de orientar aqueles que pretendem construir de uma forma ambientalmente mais responsável (BUSSOLOTI, 2007).

Portanto, uma arquitetura sustentável deve observar o espaço em que será implantada, os aspectos naturais, as condições geográficas, bem como as condições meteorológicas e topográficas, aliadas às questões sociais, econômicas e culturais do lugar (BUSSOLOTI, 2007).

No entanto, cabe destacar que as construções verdes ou sustentáveis têm projetos de alto custo econômico no Brasil. Já nos Estados Unidos, existem empresas que conseguem construir sustentavelmente com o mesmo valor que as empreiteiras tradicionais. Na verdade, essa condição só melhorará quando as pessoas estiverem conscientes dos benefícios trazidos pelas construções sustentáveis e, consequentemente, procurarem adquiri-las (NAVARRO, 2007).

Diante desses posicionamentos, afirma-se também que as construções sustentáveis devem seguir algumas diretrizes. Como exemplo, cita-se: (1) o planejamento em longo prazo para a obra; (2) eficiência energética; (3) uso adequado da água; (4) reaproveitamento da água; (5) uso de técnicas passivas das condições e recursos naturais; (6) uso de materiais e técnicas ambientalmente corretas; (7) gestão de resíduos sólidos (reciclagem, reutilização e redução); (8) conforto e qualidade interna dos ambientes; (9) permeabilidade do solo; e, (10) integração de transporte de massa ou alternativo ao contexto do projeto (BUSSOLOTI, 2007).

Além disso, economizar recursos como água e energia e reverter seus resíduos transformando-os em benefícios ou fontes de renda é um conceito inovador e bem vindo em qualquer sociedade que se preocupa com o futuro e que deseja garantir a sua continuidade (REDE DA SUSTENTABILIDADE, 2008). 
Frisa-se, portanto, que as construções sustentáveis conduzem a uma significativa melhoria para a sociedade e, consequentemente, para o design urbano das cidades, razão pela qual, examina-se no tópico subsequente exatamente isso, ou seja, quais os benefícios ocasionados pelo desenvolvimento sustentável às cidades e quais cidades já adotam essa prática, dentre outras informações inerentes a este tema tão apaixonante.

\section{SUSTENTABILIDADE URBANA}

Uma cidade é considerada sustentável, na medida em que é capaz de evitar a degradação e manter a saúde de seu sistema ambiental, reduzir a desigualdade social, prover seus habitantes de um ambiente construído saudável, bem como construir pactos políticos e ações de cidadania que o permitam enfrentar desafios presentes e futuros (URBAN WORD FORUM, 2002).

Portanto, a sustentabilidade urbana, além de preservar seus recursos naturais, deve permear a qualidade e a integração do espaço construído com os recursos naturais.

Após conceituar e esclarecer alguns pontos referentes às construções sustentáveis e a sustentabilidade urbana importante se faz observar, no tocante à implantação de cidades sustentáveis, alguns dispositivos que devem ser aplicados no design urbano, quais sejam:

a) ordenamento territorial do espaço urbano, com a formulação de Planos Diretores Municipais, seguindo a tendência dos estudos de dispersão urbana;

b) parcelamento e uso do solo em sintonia com o design desenvolvimentista que se quer da paisagem urbana;

c) adequar a administração pública com a interface do planejamento ambiental, avaliando suas características locais;

d) desenvolver sistemática que permita a efetiva participação do cidadão, seja individualmente ou através das instituições representativas;

e) promover o desenvolvimento de técnicas sustentáveis, com destaque a produção e consumo de bens e serviços, visando reduzir desperdícios; 
f) gerar incentivo ao uso de sistemas energéticos e transportes de massa de baixo índice de poluição;

g) investir na educação e cultura, através de módulos de preservação ambiental e respeitabilidade ao ser humano, especialmente voltado às gerações futuras;

h) divulgar e produzir metodologias de manutenção e conservação preventiva, com técnicas e produtos renováveis; e,

i) incentivar o desenvolvimento econômico observando a gestão dos recursos naturais.

Partindo dessas considerações, afirma-se, então, que a sustentabilidade urbana deve compreender uma série de atos e programas de sustentabilidade, para que alcance o seu objetivo, incluídas a cultura das construções verdes ou sustentáveis.

\section{CONSIDERAÇÕES FINAIS}

Das considerações estudadas, fica evidente que inserir as construções sustentáveis no contexto das cidades, reflete diretamente em aplicar as ferramentas do design urbano em benefício da sociedade, especialmente no atendimento de suas necessidades presentes, com possibilidade de gerar considerável desenvolvimento econômico, sem que afete as necessidades das futuras gerações.

Evidenciamos, inclusive, que o desenvolvimento de técnicas construtivas, aliada a aplicação de materiais ecológicos, respeitando a disponibilidade dos recursos naturais da região, produzem um positivo efeito cultural que por si só já trazem uma grande contribuição à sustentabilidade urbana.

\section{REFERÊNCIAS}

BESSA, Altamiro Mol et al. Políticas urbanas para o turismo e suas consequências nas paisagens e culturas locais: o caso recente do Rio de Janeiro (RJ). 2008. Disponível em: <http://www.ettern.ippur.ufrj.br/central_download.php?hash...id=47>. Acesso em: 
01 maio 2017.

BUSSOLOTTI, Fernando. Como funcionam as construções sustentáveis. Disponível em: <http://ambiente.hsw.uol.com.br/construcoes-ecologicas1.htm>. Acesso em: 01 maio 2017.

COELHO, Christianne C. de S. R. Complexidade e sustentabilidade nas organizações. Florianópolis, 2001. Tese (Doutorado em Engenharia de Produção) - Programa de Pós-Graduação em Engenharia de Produção, Centro Tecnológico, Universidade Federal de Santa Catarina, Florianópolis, 2001.

DOMINGUES, Alvaro (Coord.). Cidade e Democracia: 30 anos de transformação urbana em Portugal. Lisboa: Ed. Argumentum, 2006.

FERREIRA, Danilo Malta; AMADO, Rafael Fernandes. Levantamento e análise de indicadores de sustentabilidade ecológica para propostas urbanísticas. In:

CONGRESSO DE MEIO AMBIENTE DA AUGM, 6., 2009, São Carlos. Anais... São Carlos: Universidade Federal de São Carlos, 2009.

MOURA, Rosa. Cidades-modelo e a performance de Cingapura. Arquitextos, São Paulo, 2004. Disponível em: <http://www.vitruvius.com.br/arquitextos>. Acesso em: 01 maio 2017.

NAVARRO, Luciana. Construções verdes. 2007. Disponível em:

<http://clipping. planejamento.gov.br/Noticias.asp?NOTCod=386962>. Acesso em: 01 maio 2017.

REDE DE SUSTENTABILIDADE. O que é sustentabilidade? 2008. Disponível em: <http://www.sustentabilidade.org.br/>. Acesso em: 01 maio 2017.

SPANGENBERG, J. H. Sustainable Development: from catchwords to benchmarks and operational conceps. In: CHARTER M.; TISCHNER, U. (Ed.). Sustainable Solutions. Sheffield: Greenleaf Publishing Limites, 2001.

URBAN WORD FORUM. Reports On Dialogues II: sustainable urbanization. 2002. Disponível em: <http://www.unchs.org/uf/aii.html>. Acesso em: 01 maio 2017. 